\title{
Positron emission tomography alone, positron emission tomography-computed tomography and computed tomography in diagnosing recurrent cervical carcinoma: a systematic review and meta-analysis
}

\author{
Yi Xiao, Jia Wei, Yicheng Zhang, Weining Xiong
}

Department of Hematology, Tongji Hospital, Tongji Medical College, Huazhong University of Science and Technology, Wuhan, China

Submitted: 4 September 2013

Accepted: 14 September 2013

Arch Med Sci 2014; 10, 2: 222-231

DOI: 10.5114 /aoms.2014.42572

Copyright $\odot 2014$ Termedia \& Banach

\section{Abstract}

Introduction: The aim of the study was to assess systematically the accuracies of positron emission tomography (PET), PET/computed tomography $(\mathrm{CT})$, and $\mathrm{CT}$ in diagnosing recurrent cervical cancer.

Material and methods: We searched for articles published from January 1980 to June 2013 using the following inclusion criteria: articles were reported in English; the use of PET, interpreted with or without the use of CT; use of CT to detect recurrent cervical cancer; and histopathologic analysis and/ or close clinical and imaging follow-up for at least 6 months. We extracted data to calculate sensitivity, specificity, summary receiver operating characteristic curves, and the area under the receiver operating characteristic curve (AUC) as well as test for heterogeneity.

Results: In 23 included studies, PET had the highest pooled specificity at $92 \%$ (95\% Cl: 90-94), whereas PET/CT had the highest pooled sensitivity at $94 \%$ (95\% Cl: $90-97)$. The area under the curve (AUC) of PET alone, PET/CT, and CT were $0.9594,0.9508$, and 0.9363 , respectively. Results of the pairwise comparison between each modality show that the specificity of PET was higher than that of PET/CT $(p<0.05)$. The difference in the pooled sensitivities and AUC of PET alone and PET/CT showed no statistical significance. No evidence of publication bias was found. However, evidence of heterogeneity was observed.

Conclusions: The PET/CT may be a useful supplement to current surveillance techniques, particularly for patients with negative CT imaging. However, in terms of diagnostic accuracy, interpreted CT images may have limited additional value to PET in detecting recurrent cervical cancer.

Key words: recurrent cervical cancer, positron emission tomography, computed tomography, meta-analysis.

\section{Introduction}

Cervical cancer is one of the most common gynecological malignancies worldwide. Approximately $30 \%$ of cervical cancers are known to relapse eventually after initial treatment [1]. Most women who recur are not curable. However, early identification of recurrence can alter disease management or treatment-planning options, particularly for those with a central pelvic recurrence and no evidence of metastasis. A large num-

\author{
Corresponding author: \\ Yi Xiao \\ Department of Hematology \\ Tongji Hospital \\ Tongji Medical College \\ Huazhong University \\ of Science and Technology \\ 1095 Jie-Fang Avenue \\ Wuhan, Hubei, 430030 \\ P.R. China \\ Phone: 02783663611 \\ E-mail: yixia0626186@126.com
}


ber of noninvasive imaging methods can be used to identify patients with recurrent cervical cancer. These methods are used in conjunction with physical examination and measurement of squamous cell carcinoma antigen (SCC) levels. Elevated SCC values are established indicators of the active disease and can be used for early detection [2]; however, they do not identify the site of recurrence [2]. Various modalities such as computed tomography (CT) and positron emission tomography (PET) play important roles in the staging of these tumors.

Computed tomography is helpful in determining the radiation portal, site for biopsy, and effect of treatment. Consequently, this modality has been used as a very effective tool in the diagnosis of recurrent uterine cervical cancer. However, with $\mathrm{CT}$, recurrence from postoperative and postradiation fibrosis may be difficult to differentiate, and normal-sized metastatic lymph nodes are hard to detect $[3,4]$. Positron emission tomography is an emerging imaging technique that is used to diagnose cancer recurrence and distant metastasis in the preclinical stage before the disease becomes evident in conventional diagnostic imaging modalities. However, PET does not provide anatomic information, and precise localization of any suspicious lesion may be difficult. Early diagnosis of cancer recurrence by PET is also impaired by the presence of increased uptake in physiologic, nonpathologic, or inflammatory states [5, 6].

Squamous cell carcinoma measurements suffer from relatively low sensitivity and specificity for detecting recurrent cervical cancer $(76.3 \%$ and $70.6 \%$, respectively). The reported sensitivities of imaging methods range from $78 \%$ to $93 \%$ for CT, $80 \%$ to $100 \%$ for PET, $83 \%$ to $100 \%$ for PET/CT imaging, and $86 \%$ to $99 \%$ for PET using the tracer fluorine 18 (18F)-fluorodeoxyglucose (FDG). No consensus on the most sensitive imaging method for the detection of recurrence in patients treated for cervical cancer is found.

A meta-analysis enables the comparison of various imaging methods through a systematic review of the literature. The process involves combining previously published work and making a summary estimate of the sensitivity and specificity of each imaging modality [7]. The purpose of our present study is to perform a comprehensive systematic review to determine the overall diagnostic performance of PET alone, PET/CT, and CT for the detection of recurrent cervical cancer on a per-patient and a per-lesion basis. To our knowledge, this type of study has not been previously reported.

\section{Material and methods}

\section{Literature search}

A comprehensive computer literature search of study abstracts involving human subjects was performed to identify articles on the diagnostic performance of PET (interpreted with or without the use of $C T$ ) and $C T$ to detect recurrent ovarian cancer. MEDLINE and EMBASE databases were reviewed from January 1980 to June 2013 using the following key words: ("PET" or "positron emission tomography" or "FDG" or "fluorodeoxyglucose" or "CT" or "computed tomography") and ("cervical carcinoma" or "cervical cancer" or "carcinoma of cervix") and ("sensitivity" or "specificity" or "false negative" or "false positive" or "diagnosis" or "detection" or "accuracy"). Other databases, including CancerLit and the Cochrane Library, were also searched for relevant articles. Reference lists of included studies and review articles were manually searched.

\section{Selection of studies}

Two investigators independently checked the retrieved articles. Disagreements were resolved by consensus. The inclusion criteria were (a) articles were published in English; (b) PET alone, PET/ $\mathrm{CT}$, and $\mathrm{CT}$ (alone or in combination, but not in sequence) were used to identify and characterize recurrent cervical carcinoma; (c) histopathological analysis and/or close clinical follow-up for at least 6 months were used as reference; (d) for per-patient statistics, sufficient data were presented to calculate the true-positive (TP), false-negative (FN), false-positive (FP), and true-negative (TN) values; (e) 10 or more patients were included; and (f) when data or subsets of data were presented in more than one article, the article with the most detail or the most recent article was chosen. Authors of abstracts and studies that did not report sufficient data were contacted to request additional information.

\section{Data extraction}

The same observers independently extracted relevant data on study characteristics and examination results using a standardized form. To resolve disagreements between reviewers, a third reviewer assessed all discrepant items, and the majority opinion was used for analysis.

To ensure accuracy in the analyses, we extracted the following items: description of study population (age); study design (prospective, retrospective, or unknown); patient enrollment (consecutive or not); and interpretation of test results (blinded or not). The following features were also included: for PET alone or PET/CT, the amount of tracer and type of analysis (qualitative, quantitative, or both); and for CT, the section thickness and use or non-use of a contrast agent. The numbers of TP, $\mathrm{FN}, \mathrm{FP}$, and TN results in the detection of recurrent cervical cancer were extracted on a per-patient or per-lesion basis. 


\section{Statistical analysis}

The statistical software "Meta-Disc" version 1.40 was used to analyze separately the $18 \mathrm{~F}-\mathrm{FDG}$ PET, 18F-FDG PET/CT, and CT data. We calculated the pooled sensitivity, specificity, and diagnostic odds ratio (DOR) for each modality. We also calculated the summary receiver operating characteristic curves (SROC) and the ${ }^{*} \mathrm{Q}$ index (which is the optimum statistical method for reflecting the diagnostic value). The ${ }^{*} \mathrm{Q}$ index is defined by the point at which sensitivity and specificity are equal, which is closest to the ideal top-left corner of the SROC space $[8,9]$. The $Z$-test was then performed to determine whether the sensitivity, specificity, $D O R$, and ${ }^{*} Q$ index of one modality are significantly different from those of the others. The $\chi^{2}$-test was used to assess the heterogeneity among the studies included in the meta-analysis. A fixed-effect model (FEM) was used when homogeneity existed among different studies, whereas a random-effect model (REM) was used when heterogeneity was found.

\section{Results}

\section{Study identification and eligibility}

A total of 118 articles in English were initially retrieved from the MEDLINE and EMBASE databases. Twenty-six articles were considered as candidates after a review of titles and abstracts. Two articles were excluded for using CT-magnetic resonance imaging $(\mathrm{MRI})$. Finally, the remaining 23 were included in the study $[3,10-31]$.

\section{Study description}

The characteristics of participants in the 23 eligible studies are outlined in Table I. The mean age of the participants ranged from 41 years to 58 years.

Table I. Main characteristics of the included studies

\begin{tabular}{|c|c|c|c|c|c|c|c|c|}
\hline Author & $\begin{array}{l}\text { Year of } \\
\text { publica- } \\
\text { tion }\end{array}$ & $\begin{array}{l}\text { Age, mean } \\
\text { (range) }\end{array}$ & $\begin{array}{l}\text { Patients } \\
\text { selection }\end{array}$ & Blind & $\begin{array}{c}\text { Evaluable } \\
\text { patients } \\
\text { or lesion }\end{array}$ & $\begin{array}{c}\text { Recurrent } \\
\text { number } \\
n(\%)\end{array}$ & $\begin{array}{l}\text { Noninvasive } \\
\text { modalities }\end{array}$ & Study design \\
\hline Walsh & 1981 & ND (23-68) & Consecutive & ND & 33 & $29(88)$ & $\mathrm{CT}$ & Retrospectively \\
\hline Heron & 1988 & $45(28-80)$ & ND & ND & 64 & $26(41)$ & $\mathrm{CT}$ & ND \\
\hline William & 1989 & ND & ND & ND & 20 & $11(55)$ & $\mathrm{CT}$ & Retrospectively \\
\hline Park & 2000 & 53 (ND) & ND & ND & 36 & $19(53)$ & PET, CT & ND \\
\hline Sun & 2001 & ND & ND & ND & 20 & $18(90)$ & PET & Retrospectively \\
\hline Belhocine & 2002 & $52(38-66)$ & ND & ND & 60 & $28(47)$ & PET & Retrospectively \\
\hline Nakamoto & 2002 & $52(26-82)$ & ND & ND & 20 & $5(25)$ & PET & Retrospectively \\
\hline Ryu & 2003 & $51(31-78)$ & ND & ND & 249 & $31(12)$ & PET & Retrospectively \\
\hline Havrilesky & 2003 & $42(28-69)$ & ND & ND & 29 & $22(76)$ & PET & Retrospectively \\
\hline Lai & 2004 & $51(25-87)$ & Consecutive & ND & 400 & $67(17)$ & PET & Retrospectively \\
\hline Yen & 2004 & $51(25-86)$ & ND & ND & 550 & $94(17)$ & PET & Prospective \\
\hline Chang & 2004 & $54(35-76)$ & Consecutive & ND & 27 & $18(67)$ & PET & ND \\
\hline Grisaru & 2004 & $56(20-85)$ & Consecutive & Yes & 12 & $10(83)$ & $\mathrm{PET} / \mathrm{CT}$ & ND \\
\hline Sakurai & 2006 & $56(27-80)$ & Consecutive & ND & 54 & $87 \%$ & PET & ND \\
\hline Amit & 2006 & $50(31-71)$ & ND & ND & 28 & $7(25)$ & $\mathrm{PET} / \mathrm{CT}$ & ND \\
\hline Sironi & 2007 & $28-69$ & Consecutive & Yes & 12 & $5(42)$ & $\mathrm{PET} / \mathrm{CT}$ & Retrospectively \\
\hline Chung & 2007 & $53(32-77)$ & ND & ND & 32 & $28(88)$ & $\mathrm{PET} / \mathrm{CT}$ & Retrospectively \\
\hline van der Veldt & 2008 & $41(27-61)$ & ND & ND & 39 & $25(64)$ & PET & Retrospectively \\
\hline Kitajima & 2008 & $58(37-78)$ & Consecutive & Yes & 52 & $25(48)$ & $\mathrm{PET} / \mathrm{CT}, \mathrm{PET}$ & ND \\
\hline Mittra & 2009 & $50(28-87)$ & ND & ND & 30 & $24(80)$ & $\mathrm{PET} / \mathrm{CT}$ & Retrospectively \\
\hline Pallardy & 2010 & $46(35-81)$ & ND & ND & 40 & $33(83)$ & $\mathrm{PET} / \mathrm{CT}$ & Retrospectively \\
\hline Cetrina & 2011 & 47 & ND & ND & 16 & $12(75)$ & $\mathrm{PET} / \mathrm{CT}$ & Retrospectively \\
\hline Lee & 2011 & ND & ND & ND & 51 & $37(73)$ & $\mathrm{PET} / \mathrm{CT}$ & Retrospectively \\
\hline
\end{tabular}


Of the 23 studies, 1 [19] enrolled patients prospectively, whereas $15[3,11,13-18,24-26,28-31]$ were retrospective database reviews. The status of the remaining 7 studies was not defined [10, 12, 20-23, 31]. Seven studies [13, 22, 24-26, 28, 31 ] enrolled patients in a consecutive manner, including three studies $[21,24,27]$ in which the operator was blinded to prior test results. The TP, FN, FP, and TN results, as well as some features of each modality, are shown in Tables II-IV.

\section{Summary estimates of the sensitivity,} specificity, and diagnostic odds ratio

The pooled sensitivities for 18F-FDG PET, FDG$\mathrm{PET} / \mathrm{CT}$, and CT were 91\% (95\% Cl: 88-94), 94\% (95\% Cl: $90-97)$, and $89 \%$ (95\% Cl: 81-95), respectively. No statistically significant difference was found among the three noninvasive modalities $(p>0.05)$. In addition, the pooled specificities for the three modalities were $92 \%(95 \% \mathrm{Cl}$ :

Table II. TP, FP, FN, TN and other features of PET alone

\begin{tabular}{|lccccc|}
\hline Author & 18F-FDG dose & TP & FP & FN & TN \\
\hline Park & $2.5 \mathrm{MBq} / \mathrm{kg}$ & 18 & 1 & 0 & 17 \\
\hline Sun & $\mathrm{ND}$ & 16 & 0 & 2 & 2 \\
\hline Nakamoto & $370 \mathrm{MBq}$ & 5 & 6 & 0 & 9 \\
\hline Belhocine & $164.28-249.38 \mathrm{MBq}$ & 25 & 3 & 0 & 10 \\
\hline Ryu & $370-555 \mathrm{MBq}$ & 28 & 52 & 3 & 166 \\
\hline Havrilesky & $0.14 \mathrm{mCi} / \mathrm{kg}$ & 12 & 2 & 2 & 13 \\
\hline Lai & $370 \mathrm{MBq}$ & 61 & 6 & 6 & 327 \\
\hline Yen & $\mathrm{ND}$ & 84 & 8 & 10 & 448 \\
\hline Chang & $370 \mathrm{MBq}$ & 17 & 2 & 1 & 7 \\
\hline Sakurai & $200-400 \mathrm{MBq}$ & 43 & 3 & 4 & 4 \\
\hline Kitajima & $4.0 \mathrm{MBq} / \mathrm{kg}$ & 20 & 6 & 5 & 21 \\
\hline van der Veldt & $370 \mathrm{MBq}$ & 23 & 1 & 2 & 13 \\
\hline
\end{tabular}

Table III. TP, FP, FN, TN and other features of PET-CT

\begin{tabular}{|lccccc|}
\hline Author & 18 F-FDG dose & TP & FP & FN & TN \\
\hline Grisaru & $370-666 \mathrm{MBq}$ & 10 & 0 & 0 & 2 \\
\hline Chung & $555-740 \mathrm{MBq}$ & 28 & 4 & 3 & 17 \\
\hline Amit & $370-555 \mathrm{MBq}$ & 6 & 0 & 1 & 4 \\
\hline Sironi & $370 \mathrm{MBq}$ & 5 & 0 & 1 & 6 \\
\hline Kitajima & $4.0 \mathrm{MBq} / \mathrm{kg}$ & 23 & 2 & 2 & 25 \\
\hline Mittra & $400-555$ & 22 & 2 & 1 & 5 \\
\hline Pallardy & $6 \mathrm{MBq} / \mathrm{kg}$ & 31 & 1 & 2 & 6 \\
\hline Cetina & $\mathrm{ND}$ & 12 & 2 & 0 & 2 \\
\hline Lee & $370-555 \mathrm{MBq}$ & 36 & 4 & 1 & 10 \\
\hline
\end{tabular}

Table IV. TP, FP, FN, TN and other features of CT

\begin{tabular}{|lcccccc|}
\hline Author & Method & Section $[\mathrm{mm}]$ & TP & FP & FN & TN \\
\hline Wlash & Not enhanced & ND & 27 & 2 & 2 & 0 \\
\hline Heron & Not enhanced & 8 & 24 & 2 & 2 & 36 \\
\hline William & Not enhanced & ND & 10 & 2 & 1 & 7 \\
\hline Park & Not enhanced & 10 & 14 & 3 & 4 & 15 \\
\hline
\end{tabular}


Table V. Summary estimates of sensitivity, specificity, DOR, ${ }^{*} \mathrm{Q}$ index and AUC for PET, PE/CT and CT

\begin{tabular}{|lccccc|}
\hline Modality & \multicolumn{1}{c}{ Pooled sensitivity $(95 \% \mathrm{Cl})$} & Pooled specificity $(95 \% \mathrm{Cl})$ & DOR & ${ }^{*} \mathbf{Q}$ & AUC \\
\hline PET & $91 \%(88-94 \%)$ & $92 \%(90-94 \%)$ & $74.15(27.04-203.32)$ & 0.9037 & 0.9594 \\
\hline PET/CT & $94 \%(90-97 \%)$ & $84 \%(75-91 \%)$ & $62.74(27.82-141.47)$ & 0.8915 & 0.9508 \\
\hline CT & $89 \%(81-95 \%)$ & $87 \%(76-94 \%)$ & $29.31(5.46-157.31)$ & 0.8728 & 0.9363 \\
\hline
\end{tabular}

90-94), 84\% (95\% Cl: 75-91), and 87\% (95\% Cl: 76-94), respectively. Therefore, for the specificity estimates, PET had a higher pooled sensitivity $(p<0.05)$ compared with PET/CT. No statistical difference was found between PET/CT and CT in terms of their pooled specificities $(p>0.05)$. The forest plots for the sensitivities and specificities of 18F-FDG PET, FDG-PET/CT, and CT are shown in Figures 1-3.

A

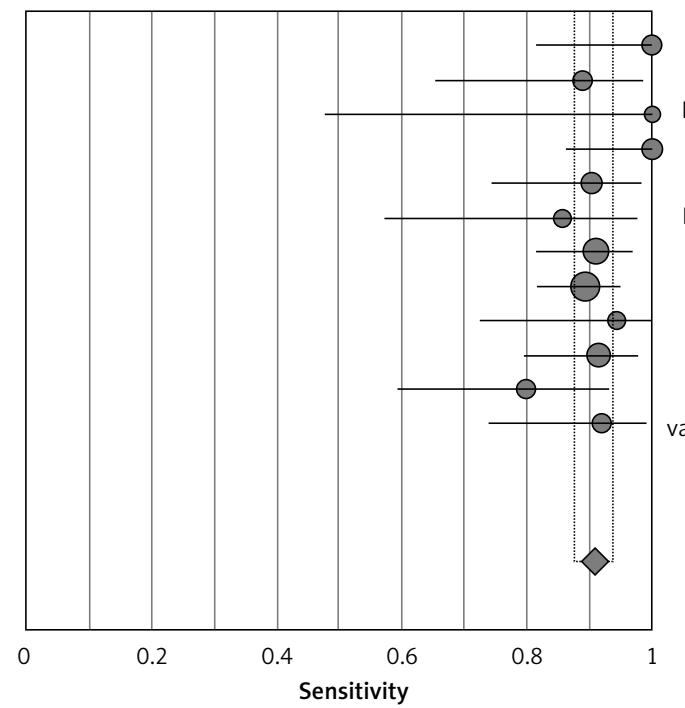

Figure 1. Sensitivity (A) and specificity (B) of PET alone

A

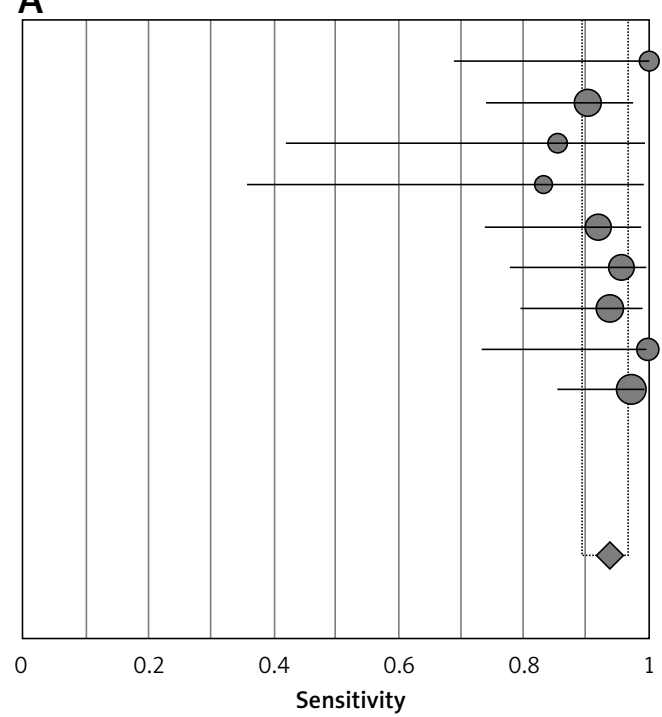

Diagnostic odds ratio expresses the odds of having the disease for people with a positive test result compared with those with a negative test result. The pooled DOR for PET alone was 74.15 (95\% Cl: 27.04-203.32), with the heterogeneity $\chi^{2}$ at $71.08(p=0.0001)$. The pooled DOR for PET/CT was 62.74 (95\% Cl: 27.82-141.47), with the heterogeneity $\chi^{2}$ at $0.00(p=0.9911)$. Meanwhile, the DOR for CT was 29.31 (95\% Cl: 5.46-157.31), with

B

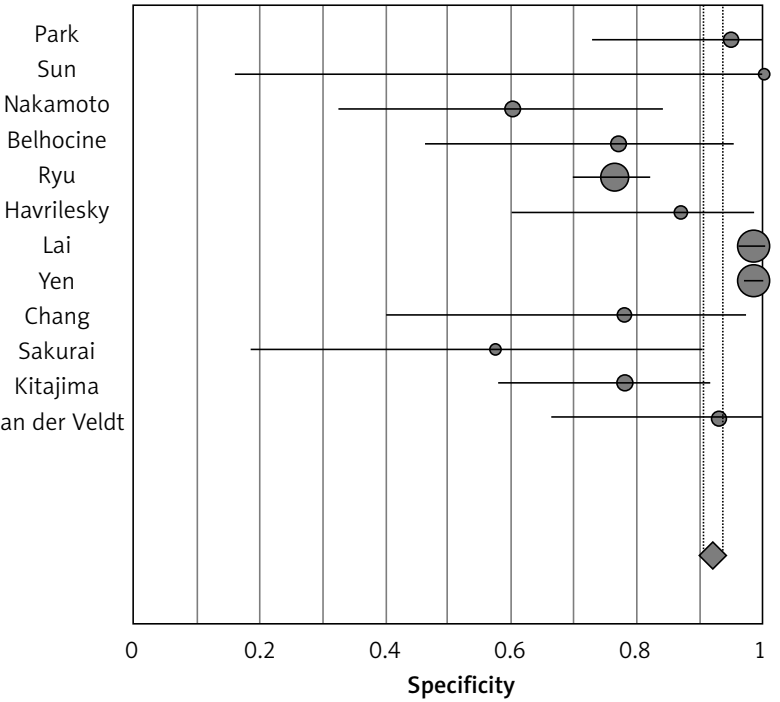

B

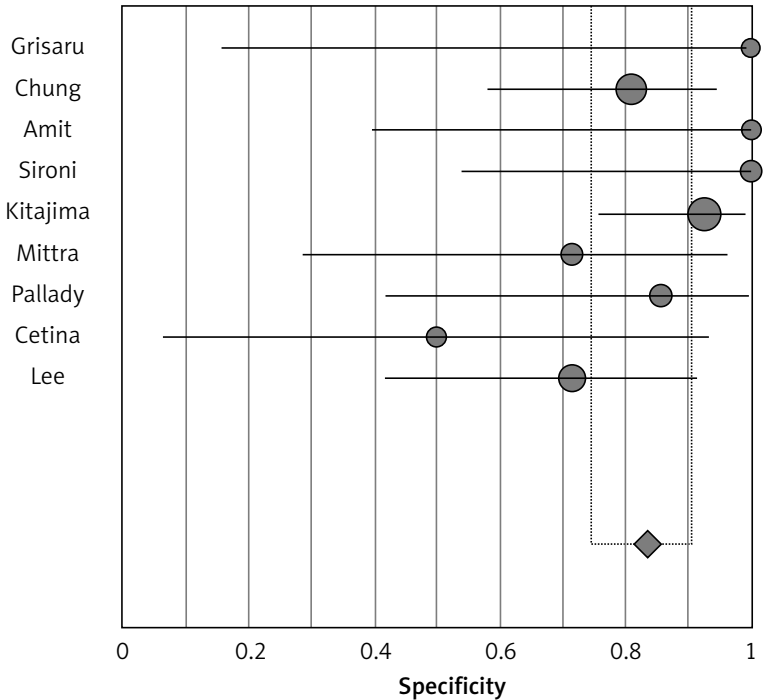

Figure 2. Sensitivity (A) and specificity (B) of PET/CT 
A

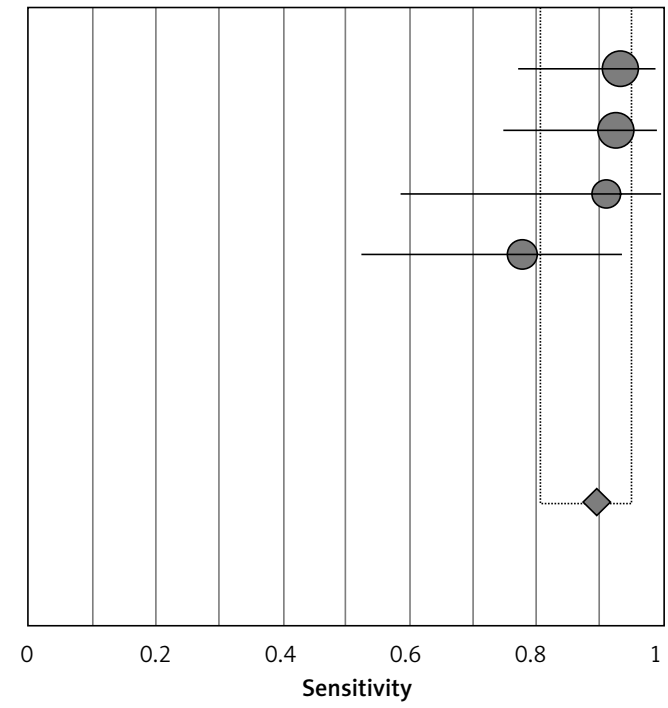

Figure 3. Sensitivity (A) and specificity (B) of CT

the heterogeneity $\chi^{2}$ at $53.5(p=0.0916)$. The results are also shown in Figure 4 (Table V).

\section{Publication bias and heterogeneity}

Begg's funnel plot and Egger's test were performed to determine the publication bias of the literature. The shapes of the funnel plots do not reveal any evidence of obvious asymmetry (Figure 5). Accordingly, Egger's test was used to provide statistical evidence of the observed funnel plot symmetry. The results still do not suggest any evidence of a publication bias ( $p$, PET $=0.681$; $p, \mathrm{PET} / \mathrm{CT}=0.677$ and $p, \mathrm{CT}=0.497)$. Regarding the limited number of data points for CT imaging, current results do not show evidence of any publication bias.

For the PET and CT studies, the specificity (heterogeneity $\chi^{2}$ : 138.75 and 11.44; $p<0.001$ and 0.0096 , respectively) was highly heterogeneous and affected the diagnostic value of PET and CT in diagnosing patients with current cervical cancer. Thus, the REMs were selected. No significant heterogeneity was found among the PET/CT studies.

\section{Summary of the receiver operating}

characteristic curves and area under the curve

We used SROC analysis to compare the noninvasive modalities. The SROC curves for $18 \mathrm{~F}-\mathrm{FDG}$ $\mathrm{PET}, \mathrm{PET} / \mathrm{CT}$, and $\mathrm{CT}$ are shown in Figure 6. Given the heterogeneity, we chose REM to synthesize the ROC curves for 18F-FDG PET and CT, whereas FEM was used for PET/CT. The AUC values of 18F-FDG PET, PET/CT, and CT were 0.9594, 0.9508, and 0.9363 , respectively (Figure 6). However, no significant difference was found among the three imaging modalities $(p>0.05)$.
B

Wlash

Heron

William

Park

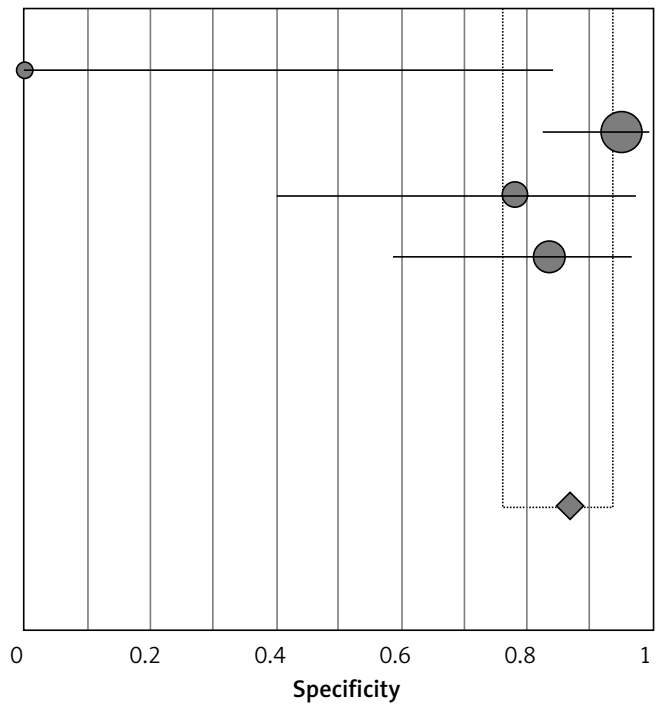

\section{Discussion}

Cancer of the uterine cervix (cervical cancer) is among the top three leading diagnoses among gynecological malignancies worldwide. This disease has a relatively high 5 -year mortality and recurrence rate (28\%). Hence, enhanced staging, therapy, and evaluation of recurrence are essential to improve the prognosis for cervical cancer patients [32]. The current meta-analysis focused on evaluating the diagnostic efficiency of PET, PET/CT, and $\mathrm{PET}$ in the diagnosis of recurrent cervical cancer.

\section{Positron emission tomography and positron emission tomography/ computed tomography}

Positron emission tomography using FDG has been successfully used to diagnose cancer recurrence and distant metastasis in the preclinical stage before the disease becomes evident by conventional imaging modalities. Positron emission tomography provides anatomical image resolutions from $4 \mathrm{~mm}$ to $6 \mathrm{~mm}$, which are significantly better than those of conventional gamma cameras but inferior to the $1 \mathrm{~mm}$ to $2 \mathrm{~mm}$ resolution of $\mathrm{CT}$ or MRI. Our results confirm that FDG-PET may be a useful modality in detecting the recurrence of cervical cancer, exhibiting high sensitivity at $91 \%$ and high specificity at 92\%. Ryu et al. [16] reported that the sensitivity and specificity of 18F-FDG PET were $90.3 \%$ and $76.1 \%$, respectively, for the detection of early recurrence in 249 patients with no evidence of the disease on physical examination and had negative tumor markers, chest radiography, and annual pelvic CT or MRI. Sugawara et al. [33] reported that 18 F-FDG PET can detect lymph node metastasis more accurately than $\mathrm{CT}$ or MRI 


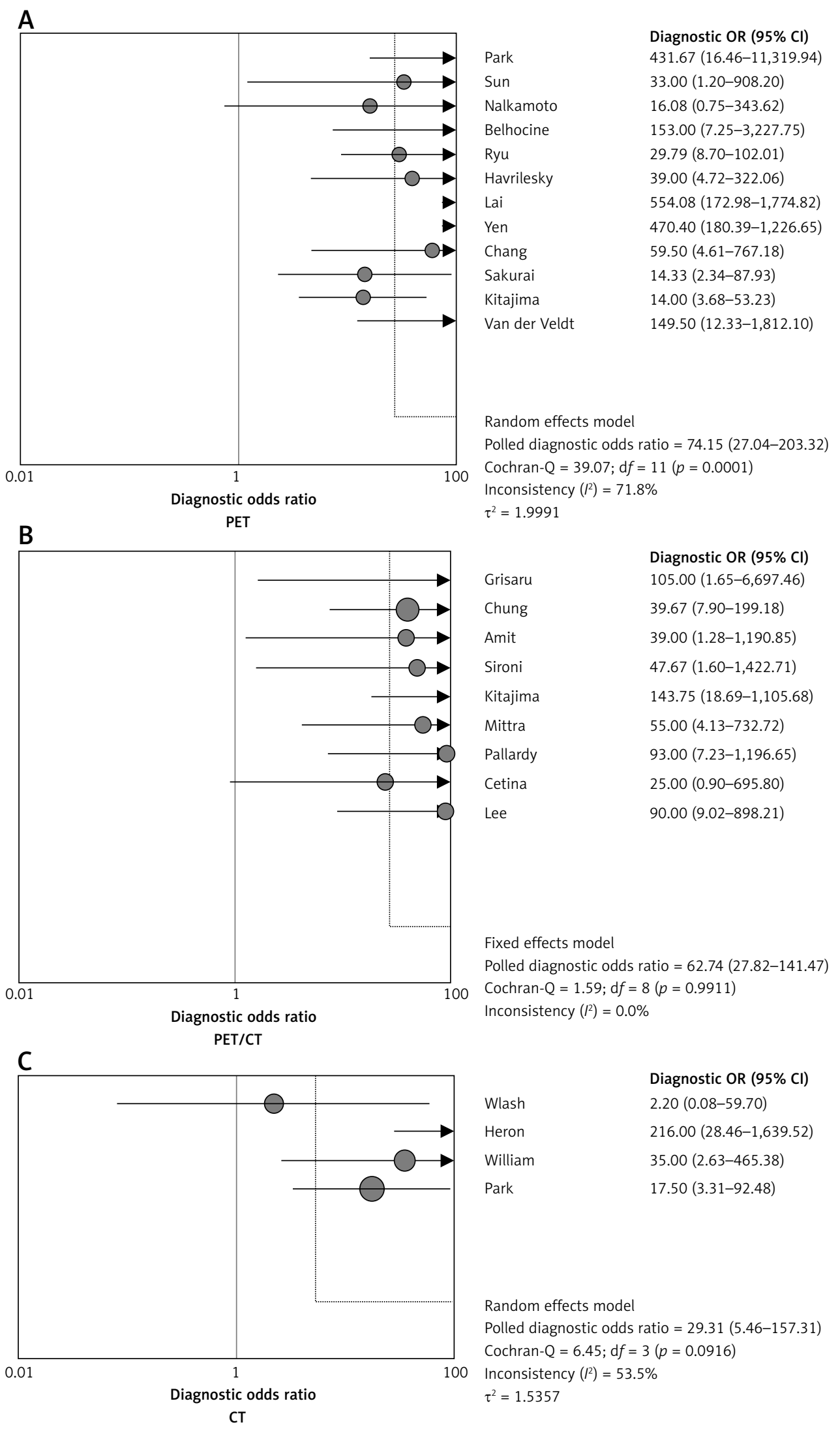

Figure 4. DOR of PET (A) alone, PET/CT (B), and CT (C) 
A Begg's funnel plot with pseudo $95 \%$ confidence limits

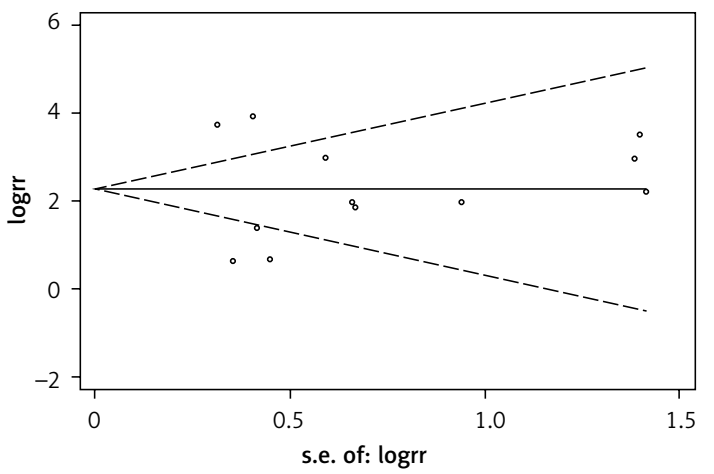

PET

B Begg's funnel plot with pseudo $95 \%$ confidence limits

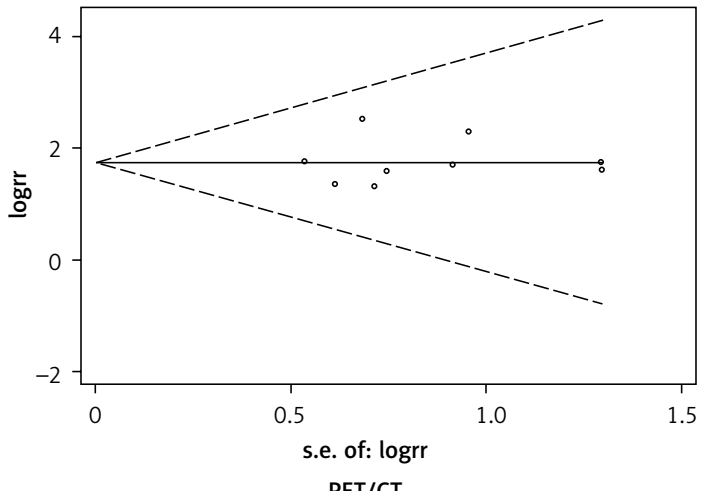

C Begg's funnel plot with pseudo $95 \%$ confidence limits

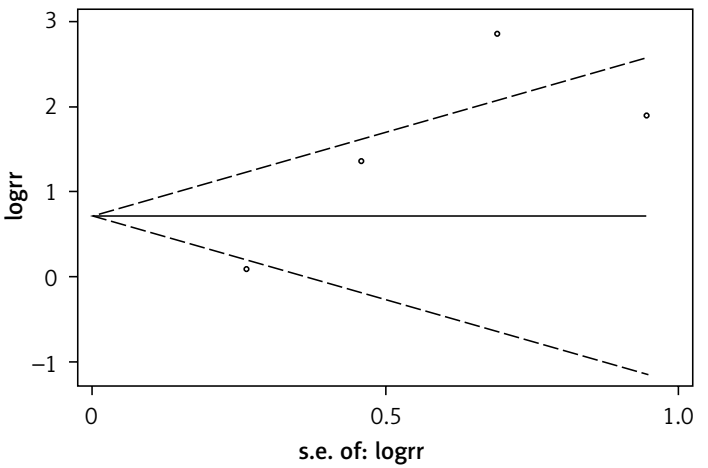

CT

Figure 5. Begg's funnel plots for assessing the publication bias risk of PET (A), PET/CT (B) and CT (C)

in patients with cervical cancer. 18F-FDG PET can detect recurrences in small lesions $(<1 \mathrm{~cm})$ and in the retrovesical area, which are frequently obscured by postradiation fibrosis. Chung et al. [25] found that the sensitivity and specificity of FDGPET for detecting recurrence in patients who had elevated serum SCC-Ag levels and negative conventional imaging findings were $94 \%$ and $78 \%$, respectively. Therefore, PET alone may be useful in the early diagnosis of recurrence, particularly when SCC levels are increasing and conventional imaging (e.g., CT or MR imaging) is inconclusive or negative. However, PET does not provide sufficient structural information for direct topographical
A

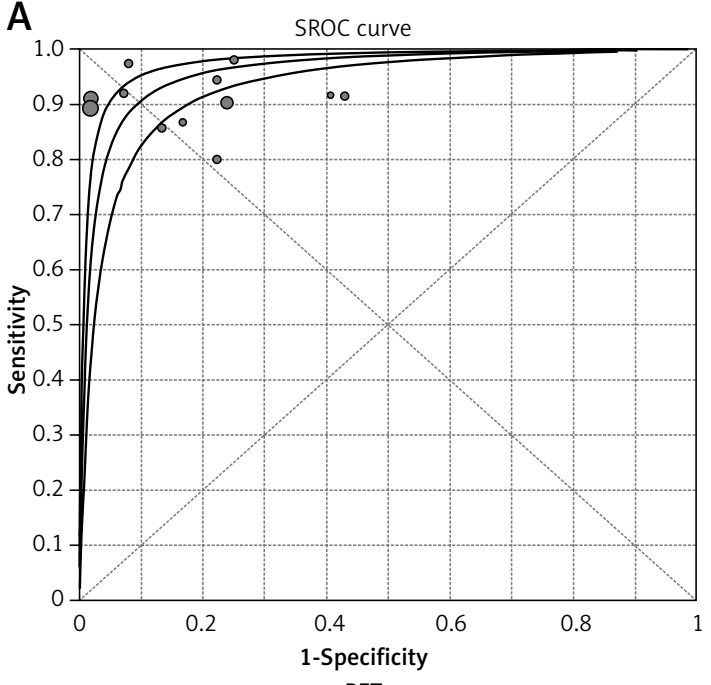

PET

Symmetric SROC $\quad$ AUC $=0.9594 \quad$ SE(AUC) -0.0098

$Q^{*}=0.9037 \quad \mathrm{SE}\left(Q^{*}\right)=0.0142$

B

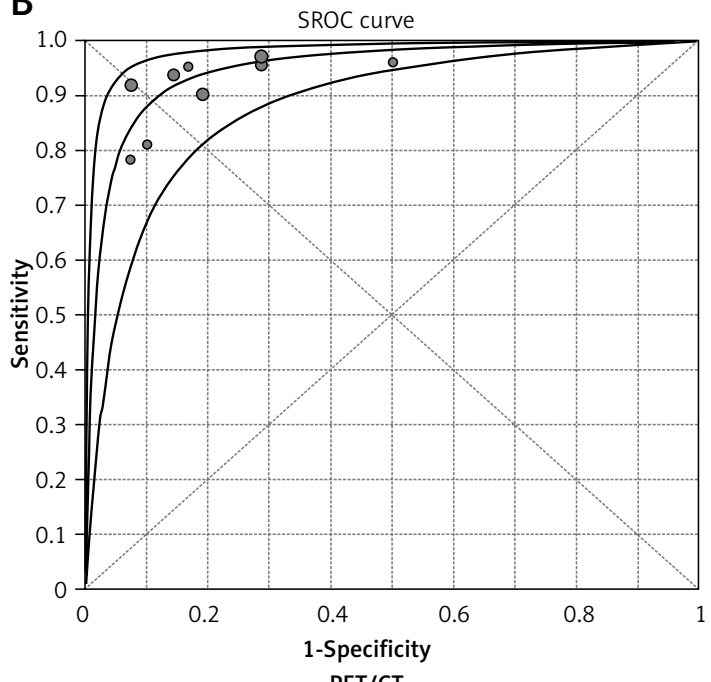

$\mathrm{PET} / \mathrm{CT}$

Symmetric SROC $\quad$ AUC $=0.9508 \quad \mathrm{SE}(\mathrm{AUC})=0.0197$

$\mathrm{Q}^{*}=0.8915 \quad \mathrm{SE}\left(\mathrm{Q}^{*}\right)=0.0267$

C

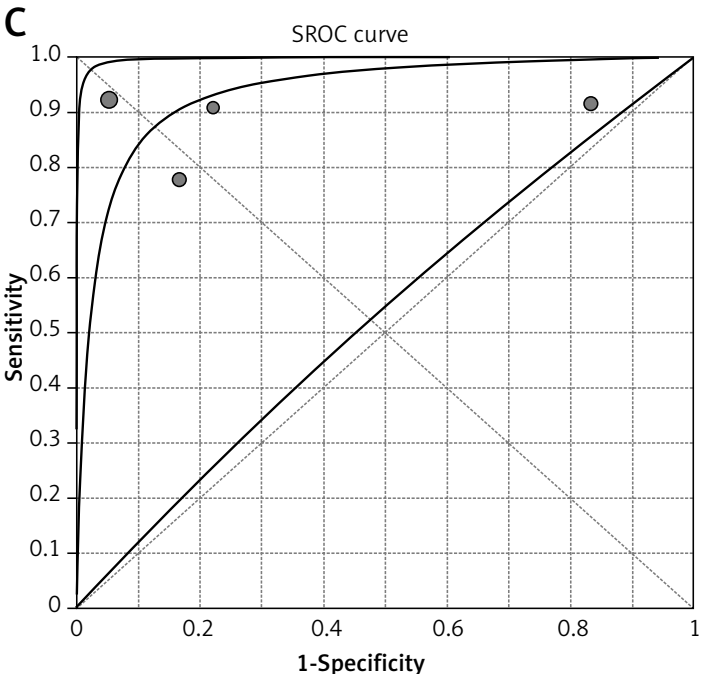

CT

Symmetric SROC $\quad$ AUC $=0.9363 \quad \mathrm{SE}(\mathrm{AUC})=0.0381$

$Q^{*}=0.8728 \quad S E\left(Q^{*}\right)=0.0472$

Figure 6. SROC curves of PET (A), PET/CT (B) and CT (C)

for detecting recurrent cervical cancer 
evaluation. Thus, image analysis has to be based on additional anatomical information [34]. An integrated PET/CT system, in which a dedicated PET ring and a multidetector helical CT are combined, has recently facilitated the acquisition of both metabolic and anatomical imaging data using a single device in a single diagnostic session. This integrated system provides precise anatomical localization of suspicious areas with increased FDG uptake and rules out false-positive PET findings [35]. The use of combined PET/CT in detecting recurrent cervical cancer was first described by Grisaru et al. in 2004. They reported that the sensitivity and specificity of PET/CT for detecting recurrent cervical cancer were both $100 \%$. A limitation of this pilot study is that the number of enrolled suspected recurrent cervical cancer patients was not sufficient for a powerful statistical analysis. In our meta-analysis, we found no significant difference between PET alone and PET/CT $(p>0.05)$. A possible explanation for this discrepancy is that the accuracy of PET/CT may have been compromised by inflammatory lesions induced by recent surgery or radiotherapy. However, the use of PET/CT can help identify biopsy sites, avoiding the interpretation problems resulting from poor anatomic localization of PET alone. A further CT scan may be based on a positive FDG PET scan.

\section{Computed tomography}

Computed tomography is often used in postoperative, follow-up examinations of patients after cervical cancer surgery. Choi et al. [36] performed a meta-analysis to assess the diagnostic performances of CT and PET or PET/CT for the detection of metastatic lymph nodes in patients with cervical cancer. Computed tomography was reported to show pooled sensitivity and specificity of $50 \%$ and $92 \%$, respectively, whereas PET or PET/CT showed $82 \%$ and $95 \%$, respectively. Park et al. [12] also reported that PET is superior to CT in terms of sensitivity and specificity. Walsh et al. [3] found that CT has difficulty in differentiating recurrence from postoperative and postradiation fibrosis and in detecting normal-sized metastatic lymph nodes. These findings suggest that PET may be crucial in detecting recurrent cervical cancer when $\mathrm{CT}$ results are negative.

\section{References}

1. Waggoner SE. Cervical cancer. Lancet 2003; 361: 2217-25.

2. Maiman $M$. The clinical application of serum squamous cell carcinoma antigen level monitoring in invasive cervical carcinoma. Gynecol Oncol 2002; 84: 4-6.

3. Walsh JW, Amendola MA, Hall DJ, Tisnado J, Goplerud DR. Recurrent carcinoma of the cervix: CT diagnosis. AJR Am J Roentgenol 1981; 136: 117-22.
4. Cunningham JJ, Fuks ZY, Castellino RA. Radiographic manifestations of carcinoma of the cervix and complications of its treatment. Radiol Clin North Am 1974; 12: 93-108.

5. Cook GJ, Maisey MN, Fogelman I. Normal variants, artefacts and interpretative pitfalls in PET imaging with 18-fluoro-2-deoxyglucose and carbon-11 methionine. Eur J Nucl Med 1999; 26: 1363-78.

6. Kostakoglu L, Agress H Jr, Goldsmith SJ. Clinical role of FDG PET in evaluation of cancer patients. Radiographics 2003; 23: 315-40; quiz 533.

7. Irwig L, Tosteson AN, Gatsonis C, et al. Guidelines for meta-analyses evaluating diagnostic tests. Ann Inter Med 1994; 120: 667-76.

8. Whiting P, Rutjes AW, Reitsma JB, Bossuyt PM, Kleijnen J. The development of QUADAS: a tool for the quality assessment of studies of diagnostic accuracy included in systematic reviews. BMC Med Res Methodol 2003; 3: 25.

9. Zamora J, Abraira V, Muriel A, Khan K, Coomarasamy A. Meta-DiSc: a software for meta-analysis of test accuracy data. BMC Med Res Methodol 2006; 6: 31.

10. Heron CW, Husband JE, Williams MP, Dobbs HJ, Cosgrove DO. The value of $C T$ in the diagnosis of recurrent carcinoma of the cervix. Clin Radiol 1988; 39: 496-501.

11. Williams MP, Husband JE, Heron CW, Cherryman GR, Koslin DB. Magnetic resonance imaging in recurrent carcinoma of the cervix. Br J Radiol 1989; 62: 544-50.

12. Park DH, Kim KH, Park SY, Lee BH, Choi CW, Chin SY. Diagnosis of recurrent uterine cervical cancer: computed tomography versus positron emission tomography. Kor J Radiol 2000; 1: 51-5.

13. Sun SS, Chen TC, Yen RF, Shen YY, Changlai SP, Kao A. Value of whole body 18F-fluoro-2-deoxyglucose positron emission tomography in the evaluation of recurrent cervical cancer. Anticancer Res 2001; 21: 2957-61.

14. Belhocine T, Thille A, Fridman V, et al. Contribution of whole-body 18FDG PET imaging in the management of cervical cancer. Gynecol Oncol 2002; 87: 90-7.

15. Nakamoto Y, Eisbruch A, Achtyes ED, et al. Prognostic value of positron emission tomography using F-18-fluorodeoxyglucose in patients with cervical cancer undergoing radiotherapy. Gynecol Oncol 2002; 84: 289-95.

16. Ryu SY, Kim MH, Choi SC, Choi CW, Lee KH. Detection of early recurrence with $18 F-F D G$ PET in patients with cervical cancer. J Nucl Med 2003; 44: 347-52.

17. Havrilesky LJ, Wong TZ, Secord AA, Berchuck A, ClarkePearson DL, Jones EL. The role of PET scanning in the detection of recurrent cervical cancer. Gynecol Oncol 2003; 90: 186-90.

18. Lai CH. Management of recurrent cervical cancer. Chang Gung Med J 2004; 27: 711-7.

19. Yen TC, See LC, Chang TC, et al. Defining the priority of using 18F-FDG PET for recurrent cervical cancer. Soc Nucl Med 2004; 45: 1632-9.

20. Chang TC, Law KS, Hong JH, et al. Positron emission tomography for unexplained elevation of serum squamous cell carcinoma antigen levels during follow-up for patients with cervical malignancies: a phase II study. Cancer 2004; 101: 164-71.

21. Grisaru D, Almog B, Levine C, et al. The diagnostic accuracy of $18 \mathrm{~F}$-fluorodeoxyglucose $\mathrm{PET} / \mathrm{CT}$ in patients with gynecological malignancies. Gynecol Oncol 2004; 94: 680-4.

22. Sakurai H, Suzuki Y, Nonaka T, et al. FDG-PET in the detection of recurrence of uterine cervical carcinoma following radiation therapy: tumor volume and FDG uptake value. Gynecol Oncol 2006; 100: 601-7. 
23. Amit A, Beck D, Lowenstein $L$, et al. The role of hybrid $\mathrm{PET} / \mathrm{CT}$ in the evaluation of patients with cervical cancer. Gynecol Oncol 2006; 100: 65-9.

24. Sironi S, Picchio M, Landoni C, et al. Post-therapy surveillance of patients with uterine cancers: value of integrated FDG PET/CT in the detection of recurrence. Eur J Nucl Med Mol Imaging 2007; 34: 472-9.

25. Chung HH, Jo H, Kang WJ, et al. Clinical impact of integrated PET/CT on the management of suspected cervical cancer recurrence. Gynecol Oncol 2007; 104: 529-34.

26. van der Veldt AA, Buist MR, van Baal MW, Comans EF, Hoekstra OS, Molthoff CF. Clarifying the diagnosis of clinically suspected recurrence of cervical cancer: impact of 18F-FDG PET. J Nucl Med 2008; 49: 1936-43.

27. Kitajima K, Murakami K, Yamasaki E, Domeki Y, Kaji Y, Sugimura K. Performance of FDG-PET/CT for diagnosis of recurrent uterine cervical cancer. Eur Radiol 2008; 18: 2040-47.

28. Mittra E, El-Maghraby T, Rodriguez CA, et al. Efficacy of 18F-FDG PET/CT in the evaluation of patients with recurrent cervical carcinoma. Eur J Nucl Med Mol Imaging 2009; 36: 1952-59.

29. Pallardy A, Bodet-Milin C, Oudoux A, et al. Clinical and survival impact of FDG PET in patients with suspicion of recurrent cervical carcinoma. Eur J Nucl Med Mol Imaging 2010; 37: 1270-8.

30. Cetina L, Serrano A, Cantú-de-León D, et al. F18-FDG$\mathrm{PET} / \mathrm{CT}$ in the evaluation of patients with suspected recurrent or persistent locally advanced cervical carcinoma. Rev Invest Clin 2011; 63: 227.

31. Lee $M$, Lee $Y$, Hwang KH, Choe W, Park CY. Usefulness of F-18 FDG PET/CT in assessment of recurrence of cervical cancer after treatment. Nucl Med Mol Imaging 2011; 45: 111-6.

32. Meads C, Auguste P, Davenport C, et al. Positron emission tomography/computerised tomography imaging in detecting and managing recurrent cervical cancer: systematic review of evidence, elicitation of subjective probabilities and economic modelling. Health Technol Assess 2013;17: 1-323.

33. Sugawara Y, Eisbruch A, Kosuda S, Recker BE, Kison PV, Wahl RL. Evaluation of FDG PET in patients with cervical cancer. J Nucl Med 1999; 40: 1125.

34. Steinmetz H, Seitz RJ. Functional anatomy of language processing: neuroimaging and the problem of individual variability. Neuropsychologia 1991; 29: 1149-61.

35. Bar-Shalom R, Yefremov N, Guralnik L, et al. Clinical performance of PET/CT in evaluation of cancer: additional value for diagnostic imaging and patient management. J Nucl Med 2003; 44: 1200-9.

36. Choi HJ, Ju W, Myung SK, Kim Y. Diagnostic performance of computer tomography, magnetic resonance imaging, and positron emission tomography or positron emission tomography/computer tomography for detection of metastatic lymph nodes in patients with cervical cancer: meta-analysis. Cancer Sci 2010; 101: 1471-9. 